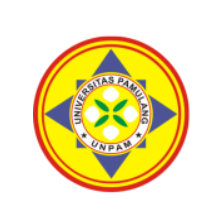

\title{
PENGARUH DISIPLIN KERJA DAN MOTIVASI TERHADAP KINERJA KARYAWAN PADA PT. POS INDONESIA KANTOR CABANG PONDOK AREN
}

\author{
${ }^{1 *}$ Irfan Rizka Akbar, ${ }^{2}$ Puji Harjianto, ${ }^{3}$ Hadi Winata \\ Universitas Pamulang, Tangerang Selatan, Banten, Indonesia \\ *dosen02461@unpam.ac.id
}

\begin{abstract}
Abstrak
Penelitian ini bertujuan untuk mengetahui pengaruh disiplin kerja dan motivasi terhadap kinerja karyawan pada PT. Pos Indonesia Kantor Cabang Pondok Aren. Metode yang digunakan adalah explanatory research dengan teknik analisis menggunakan analisis statistik dengan pengujian regresi, korelasi, determinasi dan uji hipotesis. Hasil penelitian ini disiplin kerja berpengaruh signifikan terhadap kinerja karyawan sebesar 45,8\%, uji hipotesis diperoleh $\mathrm{t}$ hitung $>\mathrm{t}$ tabel atau $(6,996>2,002)$. Motivasi berpengaruh signifikan terhadap kinerja karyawan sebesar 35,5\%, uji hipotesis diperoleh $\mathrm{t}$ hitung $>\mathrm{t}$ tabel atau $(5,652>2,002)$. Disiplin kerja dan motivasi secara simultan berpengaruh signifikan terhadap kinerja karyawan dengan persamaan regresi $Y=10,959+0,419 X 1+0,322 X 2$ dan kontribusi pengaruh sebesar 54,6\%, uji hipotesis diperoleh F hitung > F tabel atau $(34,339>2,770)$.
\end{abstract}

Kata Kunci: Disiplin Kerja, Motivasi, Kinerja Karyawan

\section{Abstract}

This study aims to determine the effect of work discipline and motivation on employee performance at PT. Pos Indonesia Pondok Aren Branch Office. The method used is explanatory research with analytical techniques using statistical analysis with regression, correlation, determination and hypothesis testing. The result of this research is that work discipline has a significant effect on employee performance by $45.8 \%$, hypothesis testing is obtained $t$ count $>t$ table or $(6,996>2,002)$. Motivation has a significant effect on employee performance by $35.5 \%$, hypothesis testing is obtained $t$ count $>t$ table or $(5.652>2.002)$. Work discipline and motivation simultaneously have a significant effect on employee performance with the regression equation $Y=10.959+$ $0.419 \times 1+0.322 X 2$ and the contribution of the influence is $54.6 \%$, hypothesis testing is obtained F count $>F$ table or $(34.339>2.770)$.

Keywords: Work Discipline, Motivation, Employee Performance

\section{PENDAHULUAN}

Pengelolaan Sumber Daya Manusia (SDM) merupakan hal yang penting dalam pencapaiaan tujuan. Umumnya pimpinan perusahaan mengharapkan kinerja yang baik dari masing-masing karyawan dalam mengerjakan tugas-tugas yang diberikan oleh perusahaan. Perusahaan menyadari bahwa Sumber Daya Manusia (SDM) merupakan modal dasar dalam proses pembangunan perusahaan bahkan nasional, oleh karena itu kualitas SDM senantiasa harus dikembangkan dan diarahkan agar tercapainya tujuan yang telah ditetapkan oleh perusahaan.

Peranan dan tantangan manajemen sumber daya manusia terus berkembang dan semakin hari semakin bertambah banyak, beraneka ragam, rumit, fleksibel dan penting seiring dengan semakin besar perusahaan, semakin rumitnya tugas yang harus di kerjakan, makin besarnya dampak lingkungan dan makin besarnya ketidak pastian yang harus dihadapi perusahaan

Disiplin yang baik mencerminkan besarnya rasa tanggung jawab seseorang terhadap tugas-tugas yang diberikan kepadanya. hal ini mendorong gairah kerja, semangat kerja dan terwujudnya perusahaan, pegawai dan masyarakat. Oleh karena itu, setiap manajer selalu berusaha agar para bawahannya mempunyai disiplin 
yang baik. Seorang manajer dikatakan efektif dalam kepemimpinannya, jika para bawahannya memiliki disiplin yang baik. Untuk memelihara dan meningkatkan kedisiplinan yang baik adalah hal yang sulit. Karena banyak faktor yang memepengaruhinya.

PT Pos Indonesia saat ini adalah salah satu perusahaan berorientasi bisnis yang melayani jasa pos dan produk-produk pendukung jasa pos. PT Pos Indonesia merupakan Perusahaan Milik Negara yang diberi subsidi dan sekaligus menjadi agen pemerintah dalam memberikan pelayanan sosial jasa pos kepada pemerintah dan masyarakat.

PT Pos Indonesia merupakan sebuah badan usaha milik negara (BUMN) Indonesia yang bergerak di bidang layanan pos. Saat ini, bentuk badan usaha Pos Indonesia merupakan perseroan terbatas dan sering disebut dengan PT Pos Indonesia. Bentuk usaha Pos Indonesia ini berdasarkan Peraturan Pemerintah Republik Indonesia Nomor 5 Tahun 1995. Peraturan Pemerintah tersebut berisi tentang pengalihan bentuk awal Pos Indonesia yang berupa perusahaan umum (perum) menjadi sebuah perusahaan (persero).

Dari sisi lain PT Pos indonesia tidak mungkin mengelola kegiatannya tanpa

Tabel 1. Data Absensi Karyawan PT Pos Indonesia Kantor Cabang Pondok Aren Periode Tahun 20142018

\begin{tabular}{|c|c|c|c|c|c|c|c|c|}
\hline \multirow[b]{2}{*}{ Tahun } & \multirow[b]{2}{*}{ JK } & \multirow[b]{2}{*}{ JHK } & \multicolumn{5}{|c|}{ Kondisi Absensi Karyawan } & \multirow[b]{2}{*}{ Persen-tase } \\
\hline & & & $\mathrm{TL}$ & I & ALP & PA & $\begin{array}{c}\text { Jumla } \\
\text { h }\end{array}$ & \\
\hline 2014 & 50 & 250 & 12 & 23 & 15 & 12 & 62 & $24,8 \%$ \\
\hline 2015 & 55 & 250 & 15 & 25 & 17 & 10 & 67 & $26,8 \%$ \\
\hline 2016 & 58 & 250 & 13 & 22 & 20 & 15 & 70 & $28,0 \%$ \\
\hline 2017 & 60 & 250 & 20 & 26 & 15 & 15 & 76 & $30,4 \%$ \\
\hline 2018 & 60 & 250 & 22 & 30 & 23 & 18 & 93 & $37,2 \%$ \\
\hline & 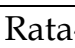 & & 16.4 & 25.2 & 18 & 14 & 73.6 & $29,4 \%$ \\
\hline
\end{tabular}

Sumber: PT Pos Indonesia Kantor Cabang Pondok Aren 2019

Berdasarkan data tabel di atas menunjukkan bahwa dari total 60 karyawan, dan rata-rata hari kerja 250 hari menunjukkan trend kondisi absensi yang flukutuatif. Tahun 2014 yang terlambat, ijin, alpha dan pulang awal mencapai $24,8 \%$, tahun 2015 sebesar 26,8\%, tahun 2016 meningkat menjadi 28,0\%, tahun 2017 dukungan sumber daya manusia, karena faktor sumber daya manusia memegang peranan yang sangat penting dalam pencapaian tujuan perusahaan. Menurut Hasibuan (2017:12) “sumber daya manusia merupakan usaha untuk menggerahkan dan mengelola sumber daya manusia di dalam organisasi agar mampu berpikir dan bertindak sebagaimana yang diinginkan oleh organisasi". Oleh karena itu, kinerja karyawan akan berjalan dengan efektif apabila didukung dengan motivasi dan disiplin kerja.

Salah satu variabel penting dalam keberhasilan organisasi dalam mencapai tujuannya adalah disiplin kerja yang mempengaruhi kinerja perusahaan. "Disiplin adalah kesadaran dan kesediaan seorang karyawan dalam mentaati semua peraturan perusahaan dan norma-norma sosial yang berlaku". (Hasibuan, 2017:94).

Dalam pelaksanaan tugas sehari-hari disiplinan sering menjadi kendala dalam sebuah organisasi, rendahnya disiplinan menjadi persoalan yang berulang-ulang terjadi. Dari hasil pra-riset yang peneliti lakukan, diperusahaan ini disiplin kerja karyawan menunjukkan kurang baik, misalnya datang terlambat, sering meninggalkan pekerjaan sebelum pada waktunya. Kondisi tersebut ditunjukkan pada data tabel berikut ini: mencapai 30,4\% dan tahun 2018 mencapai $37,2 \%$, Secara keseluruhan persentase terus meningkat dengan rata-rata $29,4 \%$.

Disiplin juga merupakan kunci terwujudnya tujuan perusahaan dengan disiplin yang baik bearti karyawan sadar dan bersedia mengerjakan tugasnya dengan baik. Dengan karyawan mematuhi 
peraturan yang telah ditetapkan oleh perusahaan dan mempunyai disiplin yang tinggi maka akan menciptakan suasana perusahaan lebih kondusif sehingga akan berdampak positif pada aktivitas perusahaan. Oleh karena itu, agar terciptanya disiplin yang baik maka manajemen mendorong atau memotivasi agar para karyawan dapat mematuhi berbagai ketentuan dan peraturan yang berlaku harus menerapkan sangsi bagi pelanggar peraturan tersebut.

Disiplin dalam penelitian ini, berhubungan dengan tingginya kinerja organisasi. Dengan kata lain, makin tinggi disiplin kerja, maka makin tinggi pula kinerja yang dihasilkan karyawan, sehingga pada akhirnya karyawan mau dan ikhlas bekerja dengan sebaik mungkin demi tercapainya tujuan organisasi dan berbagai sasarannya. Setiap organisasi mengharapkan pegawai dapat berkinerja dengan baik. Informasi mengenai kinerja pegawai diperoleh melalui penilaian kinerja.

Tabel 2. Penilaian Motivasi Kerja PT Pos Indonesia Pos Indonesia Kantor Cabang Pondok Aren Tahun 2018

\begin{tabular}{|c|c|c|c|}
\hline Unsur yang dinilai & Nilai & Capaian & Jumlah \\
\hline Tantangan pekerjaan & 65.00 & Cukup & 65.00 \\
\hline Tanggung jawab pekerjaan & 55.00 & Sedang & 55.00 \\
\hline Prestasi kerja & 53.00 & Sedang & 53.00 \\
\hline Kesejahteraan & 60.00 & Sedang & 60.00 \\
\hline Jabatan & 45.00 & Buruk & 45.00 \\
\hline Hubungan kerja & 69.00 & Cukup & 69.00 \\
\hline Harapan & 75.00 & Cukup & 75.00 \\
\hline Penghargaan & 47.00 & Buruk & 47.00 \\
\hline Jumlah & 469.00 & & 469.00 \\
\hline Nilai rata-rata & 58.62 & Sedang & \\
\hline
\end{tabular}

Kriteria: $=50$ (Buruk),$<=60$ (Sedang),$<=70($ Cukup),$<=90$ (Baik),$<=99$ (Sangat Baik)

Berdasarkan data pada tabel di atas, memperlihatkan bahwa secara keseluruhan nilai pencapaian motivasi kerja pada PT Pos Indonesia dari tahun 2018 menunjukkan pencapaian yang tidak maksimal. Motivasi pada mencapai jabatan tertentu dan adanya harapan untuk mendapatkan penghargaan hasilnya buruk, sedangkan tantangan pekerjaan dengan nilai cukup serta tanggung jawab pekerjaan dan adanya harapan akan adanya kesejahteraan karyawan hanya pada tingkat penilaian sedang. Tabel ini menunjukan bahwa memerlukan perhatian yang serius bagi manajemen perusahaan.

Berdasarkan data empirik ada beberapa masalah yang dapat berpengaruh kinerja diantaranya beban kerja dan kepuasan kerja. Dari hasil yang dilakukan, perihal kinerja pada PT Pos Indonesia menunjukkan trend yang cenderung menurun. Berikut ini hasil evaluasi penilaian kinerja pegawai di PT Pos Indonesia periode 2013-2017 yang ditampilkan pada tabel dibawah ini: 
Tabel 3. Pengukuran Kinerja Program PT Pos Indonesia Kantor Cabang Pondok Aren

\begin{tabular}{|c|c|c|c|c|c|c|}
\hline \multirow[b]{2}{*}{ Tahun } & \multirow{2}{*}{$\begin{array}{c}\text { Jumlah } \\
\text { Karyawa } \\
n\end{array}$} & \multicolumn{4}{|c|}{ Aspek } & \multirow[b]{2}{*}{$\begin{array}{c}\text { Persentas } \\
\text { e }\end{array}$} \\
\hline & & $\begin{array}{c}\text { Penghargaa } \\
n\end{array}$ & $\begin{array}{c}\text { Kuantita } \\
\text { s }\end{array}$ & Kualitas & $\begin{array}{c}\text { Kemampua } \\
\mathrm{n}\end{array}$ & \\
\hline 2014 & 50 & 45 & 45 & 40 & 42 & $86.0 \%$ \\
\hline 2015 & 55 & 40 & 42 & 41 & 38 & $73.2 \%$ \\
\hline 2016 & 58 & 42 & 38 & 36 & 39 & $66.8 \%$ \\
\hline 2017 & 60 & 44 & 40 & 42 & 40 & $69.2 \%$ \\
\hline 2018 & 60 & 38 & 36 & 41 & 37 & $63.3 \%$ \\
\hline \multicolumn{2}{|c|}{ Rata-rata } & 42 & 40 & 40 & 39 & $71.7 \%$ \\
\hline
\end{tabular}

Sumber: PT Pos Indonesia Kantor Cabang Pondok Aren 2019

Berdasarkan data tabel di atas menunjukkan bahwa dari total 60 karyawan, menunjukan pengukuran kinerja dari tahun 2014 sampai dengan 2018 Keseluruhan aspek rata-rata berada pada pencapaian hanya sebesar $71,7 \%$. Pencapaian kerja berada pada tataran yang masih terkoreksi. tabel di atas menunjukkan bahwa secara keseluruhan kinerja masih perlu adanya peningkatan agar memenuhi harapan yang diinginkan sehingga tugas dan kewajiban yang diberikan dapat mencapai target yang ditentukan. Pada dasarnya setiap organisasi mempunyai harapan agar karyawan perusahaan dapat mematuhi peraturan yang telah ditetapkan.

Menurut Mangkunegara (2015:67) kinerja merupakan hasil kerja secara kualitas atau kuantitas yang dicapai oleh seseorang pegawai dalam melaksanakan tugasnya sesuai dengan tanggung jawab yang diberikan kepadanya". Sedangkan menurut Hasibuan (2017:100) "Kinerja adalah hasil kerja yang dicapai setiap karyawan sehingga dapat memberikan kontribusi positif terhadap perusahaan".

Maka dari hasil evaluasi maka peneliti tertarik untuk melakukan penelitian yang berjudul "Pengaruh Disiplin Kerja dan Motivasi Terhadap Kinerja Karyawan Pada PT Pos Indonesia Kantor Cabang Pondok Aren".

\section{TINJAUAN PUSTAKA}

\section{Disiplin Kerja}

Yang dimaksud disiplin kerja dalam penelitian ini kesadaran dan kesediaan seseorang menaati semua peraturan dan peraturan-peraturan yang berlaku Menurut Hasibuan (2016:194). Adapun indikator yang digunakan meliputi: 1) Tujuan dan kemampuan karyawan, 2) keteladanan dari pimpinan, 3) pemberian balas jasa, 4) pemberian sanksi dan hukuman serta 5) ketegasan dalam menegakkan peraturan.

2. Motivasi

Yang dimaksud motivasi merupakan seperangkat kekuatan baik yang berasal dari dalam diri maupun dari luar diri seseorang yang mendorong untuk memulai berperilaku kerja sesuai dengan format, arah, intensitas dan jangka waktu tertentu (David McCleland dalam Miftah Toha, 2016:235). Adapun indikator yang digunakan meliputi: 1) Kebutuhan berprestasi (Need of Achievement), 2) kebutuhan untuk berkuasa atau mempengaruhi orang lain ((Need of Power), 3) kebutuhan berafiliasi (Need of Affilliation)

\section{Kinerja Karyawan}

Dalam penelitian ini yang dijadikan variabel dependen adalah kinerja karyawan yang diartikan sebagai suatu hasil kerja secara kualitas dan kuantitas yang dicapai oleh seorang pegawai dalam melaksanakan tugasnya sesuai dengan tanggung jawab yang diberikan kepadanya (Mangkunegara, 2015:67). Adapun indikator yang digunakan meliputi: 1) kualitas kerja, 2) kuantitas kerja, 3) bertanggung jawab, 4) sikap dalam bekerja.

\section{METODE}

Populasi dalam penelitian ini berjumlah 60 responden PT. Pos Indonesia Kantor Cabang Pondok Aren. Sampel dalam penelitian ini berjumlah 60 responden. Jenis penelitian yang dipakai 
adalah kuantitatif, dimana tujuannya adalah untuk mengetahui pengaruh antara variabel bebas terhadap variabel terikat baik parsial maupun simultan . Dalam menganalisis data digunakan uji instrumen, uji asumsi klasik, regresi, koefisien korelasi, koefisien determinasi dan uji hipotesis.
HASIL DAN PEMBAHASAN

\section{Analisis Deskriptif}

Pada pengujian ini digunakan untuk mengetahui skor minimum dan maksimum, mean score dan standar deviasi dari masing-masing variabel. Adapun hasilnya sebagai berikut:

Tabel 4. Hasil Analisis Descriptive Statistics

Descriptive Statistics

\begin{tabular}{l|r|r|r|r|r} 
& N & Minimum & Maximum & Mean & Std. Deviation \\
\hline Disiplin Kerja (X1) & 60 & 31 & 48 & 38.25 & 4.301 \\
\hline Motivasi (X2) & 60 & 31 & 48 & 38.28 & 3.818 \\
\hline Kinerja Karyawan (Y) & 60 & 33 & 46 & 39.32 & 3.572 \\
\hline Valid N (listwise) & 60 & & & & \\
\hline
\end{tabular}

Disiplin kerja diperoleh varians minimum sebesar 31 dan varians maximum 48 dengan mean score sebesar 38,25 dengan standar deviasi 4,301.

Motivasi diperoleh varians minimum sebesar 31 dan varians maximum 48 dengan mean score sebesar 38,28 dengan standar deviasi 3,818.

Kinerja karyawan diperoleh varians minimum sebesar 33 dan varians maximum 46 dengan mean score sebesar 39,32 dengan standar deviasi 3,572.

\section{Analisis Verifikatif.}

Pada analisis ini dimaksudkan untuk mengetahui pengaruh variabel independen terhadap variabel dependen. Adapun hasil pengujian sebagai berikut:

a. Analisis Regresi Linier Berganda

Uji regresi ini dimaksudkan untuk mengetahui perubahan variabel dependen jika variabel independen mengalami perubahan. Adapun hasil pengujiannya sebagai berikut:

Tabel 5. Hasil Pengujian Regresi Linier Berganda

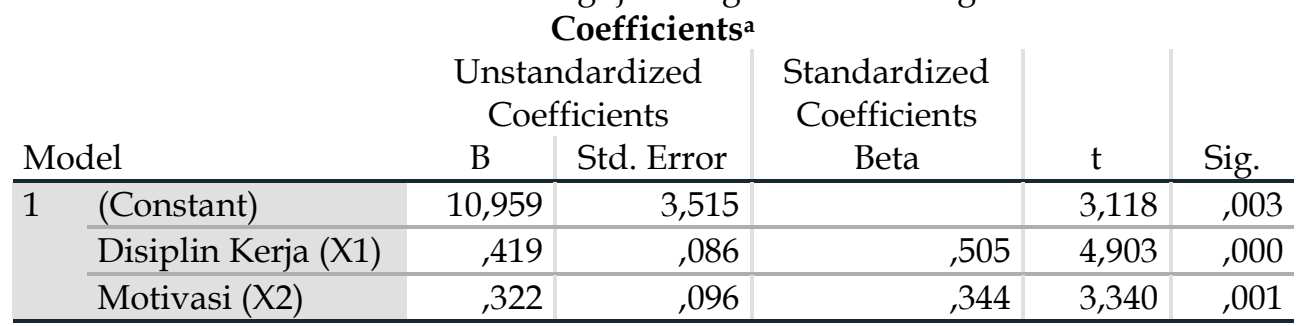

a. Dependent Variable: Kinerja Karyawan (Y)

Berdasarkan hasil pengujian pada tabel di atas, diperoleh persamaan regresi $\mathrm{Y}=10,959+$ 0,419X1 + 0,322X2. Dari persamaan tersebut dijelaskan sebagai berikut:

1) Konstanta sebesar 10,959 diartikan jika disiplin kerja dan motivasi tidak ada, maka telah terdapat nilai kinerja karyawan sebesar 10,959 point.

2) Koefisien regresi disiplin kerja sebesar 0,419, angka ini positif artinya setiap ada peningkatan disiplin kerja sebesar 0,419 maka kinerja karyawan juga akan mengalami peningkatan sebesar 0,419 point.

3) Koefisien regresi motivasi sebesar 0,322, angka ini positif artinya setiap ada peningkatan motivasi sebesar 0,322 maka kinerja karyawan juga akan mengalami peningkatan sebesar 0,322 point.

\section{b. Analisis Koefisien Korelasi}

Analisis koefisien korelasi dimaksudkan untuk mengetahui tingkt kekuatan hubungan dari 
variabel independen terhadap maupun simultan. Adapun hasil variabel dependen baik secara parsial pengujian sebagai berikut:

Tabel 6. Hasil Pengujian Koefisien Korelasi Disiplin kerja Terhadap Kinerja Karyawan.

\begin{tabular}{|c|c|c|c|}
\hline & \multicolumn{2}{|c|}{ Correlations $^{b}$} & \multirow[b]{2}{*}{$\begin{array}{c}\text { Kinerja } \\
\text { Karyawan (Y) }\end{array}$} \\
\hline & & $\begin{array}{l}\text { Disiplin Kerja } \\
(X 1)\end{array}$ & \\
\hline \multirow[t]{2}{*}{ Disiplin Kerja (X1) } & Pearson Correlation & 1 & $677^{* *}$ \\
\hline & Sig. (2-tailed) & & ,000 \\
\hline \multirow[t]{2}{*}{ Kinerja Karyawan (Y) } & Pearson Correlation & $677^{* *}$ & 1 \\
\hline & Sig. (2-tailed) & ,000 & \\
\hline
\end{tabular}

Berdasarkan hasil pengujian hubungan yang kuat terhadap kinerja diperoleh nilai korelasi sebesar 0,677 artinya disiplin kerja memiliki karyawan.

Tabel 7. Hasil Pengujian Koefisien Korelasi Motivasi Terhadap Kinerja Karyawan.

Correlations $^{b}$

\begin{tabular}{llr|r} 
& & \multicolumn{2}{c}{$\begin{array}{c}\text { Kinerja } \\
\text { Karyawan (Y) }\end{array}$} \\
\hline Motivasi (X2) & Pearson Correlation & 1 &, $596^{* *}$ \\
\cline { 2 - 4 } & Sig. (2-tailed) & &, 000 \\
\hline Kinerja Karyawan (Y) & Pearson Correlation &, $596^{* *}$ & 1 \\
\cline { 2 - 4 } & Sig. (2-tailed) &, 000 & \\
\hline
\end{tabular}

**. Correlation is significant at the 0.01 level (2-tailed).

b. Listwise $\mathrm{N}=60$

Berdasarkan hasil pengujian diperoleh nilai korelasi sebesar 0,596 yang sedang terhadap kinerja artinya motivasi memiliki hubungan karyawan.

Tabel 8. Hasil Pengujian Koefisien Korelasi Disiplin kerja dan Motivasi secara simultan Terhadap Kinerja Karyawan.

Model Summary

\begin{tabular}{lr|r|r|r} 
Model & $\mathrm{R}$ & \multicolumn{2}{|c|}{$\begin{array}{c}\text { Adjusted R } \\
\text { Square }\end{array}$} & $\begin{array}{c}\text { Std. Error of the } \\
\text { Estimate }\end{array}$ \\
\hline 1 &, $739^{\mathrm{a}}$ &, 546 &, 531 & 2,448 \\
\hline
\end{tabular}

a. Predictors: (Constant), Motivasi (X2), Disiplin Kerja (X1)

Berdasarkan hasil pengujian diperoleh nilai korelasi sebesar 0,739 artinya disiplin kerja dan motivasi secara simultan memiliki hubungan yang kuat terhadap kinerja karyawan.

\section{c. Analisis Koefisien Determinasi}

Analisis koefisien determinasi dimaksudkan untuk mengetahui besarnya persentase pengaruh dari variabel independen terhadap variabel dependen baik secara parsial maupun simultan. Adapun hasil pengujian sebagai berikut:

Tabel 9. Hasil Pengujian Koefisien Determinasi Disiplin kerja Terhadap Kinerja Karyawan.

\section{Model Summary}

\begin{tabular}{lr|r|r|rr} 
Model & \multicolumn{2}{|c|}{$\begin{array}{c}\text { Adjusted R } \\
\text { Square }\end{array}$} & \multicolumn{2}{c}{$\begin{array}{c}\text { Std. Error of the } \\
\text { Estimate }\end{array}$} \\
\hline 1 & $\mathrm{R}$ & R Square & \multicolumn{2}{c}{ Squar } \\
\hline
\end{tabular}

a. Predictors: (Constant), Disiplin Kerja (X1) 
Berdasarkan hasil pengujian diperoleh nilai determinasi sebesar 0,458 artinya disiplin kerja memiliki

Tabel 10. Hasil Pengujian Koefisien Determinasi Motivasi Terhadap Kinerja Karyawan.

\section{Model Summary}

\begin{tabular}{l|r|r|rr} 
Model & $\mathrm{R}$ & \multicolumn{2}{|c|}{$\begin{array}{c}\text { Adjusted R } \\
\text { S Square }\end{array}$} & $\begin{array}{c}\text { Std. Error of the } \\
\text { Estimate }\end{array}$ \\
\hline 1 &, $596^{\mathrm{a}}$ &, 355 &, 344 & 2,893 \\
\hline a. Predictors: (Constant), Motivasi (X2) & &
\end{tabular}

Berdasarkan hasil pengujian diperoleh nilai determinasi sebesar 0,355 artinya motivasi memiliki kontribusi pengaruh sebesar 35,5\% terhadap kinerja karyawan.

kontribusi pengaruh sebesar $45,8 \%$ terhadap kinerja karyawan.

Tabel 11. Hasil Pengujian Koefisien Determinasi Disiplin kerja dan Motivasi Terhadap Kinerja Karyawan.

Model Summary

\begin{tabular}{lr|r|r|rr} 
Model & $\mathrm{R}$ & R Square & $\begin{array}{c}\text { Adjusted R } \\
\text { Square }\end{array}$ & \multicolumn{2}{|c}{$\begin{array}{c}\text { Std. Error of the } \\
\text { Estimate }\end{array}$} \\
\hline 1 &, $739^{\mathrm{a}}$ &, 546 &, 531 & 2,448 \\
\hline
\end{tabular}

a. Predictors: (Constant), Motivasi (X2), Disiplin Kerja (X1)

Berdasarkan hasil pengujian diperoleh nilai determinasi sebesar 0,546 artinya disiplin kerja dan motivasi secara simultan memiliki kontribusi pengaruh sebesar $54,6 \%$ terhadap kinerja karyawan, sedangkan sisanya sebesar $45,4 \%$ dipengaruhi faktor lain.

\section{d. Uji Hipotesis}

Uji hipotesis Parsial (Uji t)

Pengujian hipotesis dengan uji $t$ digunakan untuk mengetahui hipotesis parsial mana yang diterima.

Hipotesis pertama: Terdapat pengaruh yang signifikan antara disiplin kerja terhadap kinerja karyawan.

Tabel 12. Hasil Uji Hipotesis Disiplin kerja Terhadap Kinerja Karyawan.

\section{Coefficients $^{\mathrm{a}}$}

Unstandardized

Coefficients

Standardized

Coefficients

\begin{tabular}{|c|c|c|c|c|c|}
\hline \multirow[b]{2}{*}{ del } & & \multirow{2}{*}{ Beta } & & \multirow[b]{2}{*}{ Sig. } \\
\hline & B & Std. Error & & & \\
\hline (Constant) & 17,821 & 3,091 & & 5,765 & ,000 \\
\hline Disiplin Kerja (X1) & ,562 & 080 & 677 & 6,996 & 000 \\
\hline
\end{tabular}

a. Dependent Variable: Kinerja Karyawan (Y)

Berdasarkan hasil pengujian pada tabel di atas, diperoleh nilai $t$ hitung > t tabel atau $(6,996>2,002)$, dengan demikian hipotesis pertama

Tabel 13. Hasil Uji Hipotesis Motivasi Terhadap Kinerja Karyawan.

yang diajukan bahwa terdapat pengaruh yang signifikan atara disiplin kerja terhadap kinerja karyawan diterima.

Coefficients ${ }^{\mathrm{a}}$

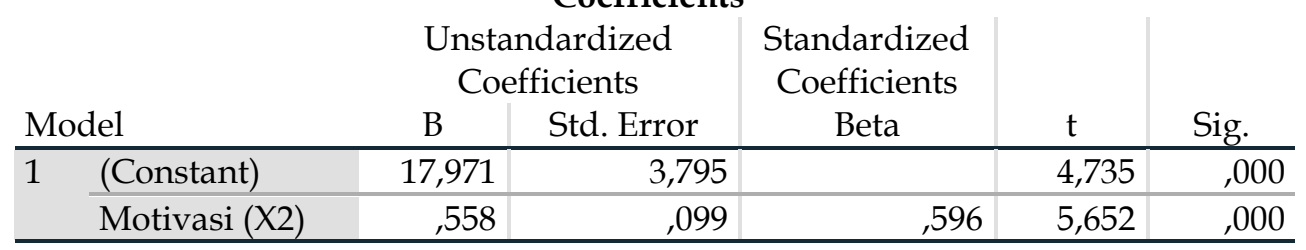

a. Dependent Variable: Kinerja Karyawan (Y)

Berdasarkan hasil pengujian

pada tabel di atas, diperoleh nilai $\mathrm{t}$ 
hitung $>\mathrm{t}$ tabel atau $(5,652>2,002)$, dengan demikian hipotesis kedua yang diajukan bahwa terdapat pengaruh yang signifikan atara motivasi terhadap kinerja karyawan diterima.
Uji Hipotesis Simultan (Uji F)

Pengujian hipotesis dengan uji $\mathrm{F}$ digunakan untuk mengetahui hipotesis simultan yang mana yang diterima.

Hipotesis ketiga Terdapat pengaruh yang signifikan antara disiplin kerja dan motivasi terhadap kinerja karyawan.

Tabel 14. Hasil Uji Hipotesis Disiplin kerja dan Motivasi Terhadap Kinerja Karyawan.

\begin{tabular}{|c|c|c|c|c|c|c|}
\hline \multirow{2}{*}{\multicolumn{2}{|c|}{ Model }} & \multirow{3}{*}{$\begin{array}{l}\begin{array}{l}\text { Sum of } \\
\text { Squares }\end{array} \\
411,475\end{array}$} & \multicolumn{2}{|c|}{ ANOVA $^{a}$} & \multirow[b]{2}{*}{$\mathrm{F}$} & \multirow{3}{*}{$\frac{\text { Sig. }}{, 000}$} \\
\hline & & & $\mathrm{df}$ & Mean Square & & \\
\hline \multirow[t]{3}{*}{1} & Regression & & 2 & 205,738 & 34,339 & \\
\hline & Residual & 341,508 & 57 & 5,991 & & \\
\hline & Total & 752,983 & 59 & & & \\
\hline
\end{tabular}

a. Dependent Variable: Kinerja Karyawan (Y)

b. Predictors: (Constant), Motivasi (X2), Disiplin Kerja (X1)

Berdasarkan hasil pengujian pada tabel di atas, diperoleh nilai $\mathrm{F}$ hitung > F tabel atau $(34,339>2,770)$, dengan demikian hipotesis ketiga yang diajukan bahwa terdapat pengaruh yang signifikan atara disiplin kerja dan motivasi terhadap kinerja karyawan diterima.

\section{PEMBAHASAN HASIL PENELITIAN}

1. Pengaruh Disiplin kerja Terhadap Kinerja Karyawan

Disiplin kerja berpengaruh signifikan terhadap kinerja karyawan dengan korelasi sebesar 0,677 atau memiliki hubungan yang kuat dengan kontribusi pengaruh sebesar 45,8\%. Pengujian hipotesis diperoleh nilai $t$ hitung $>\mathrm{t}$ tabel atau $(6,996>2,002)$. Dengan demikian hipotesis pertama yang diajukan bahwa terdapat berpengaruh signifikan antara disiplin kerja terhadap kinerja karyawan diterima.

\section{Pengaruh Motivasi Terhadap Kinerja Karyawan}

Motivasi berpengaruh signifikan terhadap kinerja karyawan dengan korelasi sebesar 0,596 atau memiliki hubungan yang sedang dengan kontribusi pengaruh sebesar 35,5\%.
Pengujian hipotesis diperoleh nilai $t$ hitung $>\mathrm{t}$ tabel atau $(5,652>2,002)$. Dengan demikian hipotesis kedua yang diajukan bahwa terdapat berpengaruh signifikan antara motivasi terhadap kinerja karyawan diterima.

\section{Pengaruh Disiplin kerja dan Motivasi Terhadap Kinerja Karyawan}

Disiplin kerja dan motivasi berpengaruh signifikan terhadap kinerja karyawan dengan diperoleh persamaan regresi $Y=10,959+0,419 X 1+0,322 X 2$, nilai korelasi sebesar 0,739 atau memiliki hubungan yang kuat dengan kontribusi pengaruh sebesar $54,6 \%$ sedangkan sisanya sebesar $45,4 \%$ dipengaruhi faktor lain. Pengujian hipotesis diperoleh nilai $\mathrm{F}$ hitung > F tabel atau $(34,339>2,770)$. Dengan demikian hipotesis ketiga yang diajukan bahwa terdapat berpengaruh signifikan antara disiplin kerja dan motivasi terhadap kinerja karyawan diterima.

\section{PENUTUP}

\section{Kesimpulan}

1. Disiplin kerja berpengaruh signifikan terhadap kinerja karyawan dengan kontribusi pengaruh sebesar $45,8 \%$. Uji hipotesis diperoleh nilai thitung $>\mathrm{t}$ tabel atau $(6,996>2,002)$. 
2. Motivasi berpengaruh signifikan terhadap kinerja karyawan dengan kontribusi pengaruh sebesar $35,5 \%$. Uji hipotesis diperoleh nilai $\mathrm{t}$ hitung $>\mathrm{t}$ tabel atau $(5,652>2,002)$.

3. Disiplin kerja dan motivasi berpengaruh signifikan terhadap kinerja karyawan dengan kontribusi pengaruh sebesar $54,6 \%$ sedangkan sisanya sebesar $45,4 \%$ dipengaruhi faktor lain. Uji hipotesis diperoleh nilai $\mathrm{F}$ hitung $>\mathrm{F}$ tabel atau $(34,339>2,770)$.

\section{Saran}

1. Perusahaan harus secara serius menerapkan peraturan dengan tegas dan tanpa memandang posisi jabatan tertentu sehingga hubungan kinerja antar karyawan dapat berjalan dengan baik.

2. Perusahaan harus meberikan kesempatan kepada setiap karyawan atau pegawai untuk berlomba-lomba menunjukkan prestasi kerja yang optimal sehingga dapat dijadikan pertimbangan dalam karirnya.

3. Pimpinan harus mampu menunjukkan sikap dan memberi contoh kepada bawahannya bagaimana bekerja secara efektif dengan tingkat kualitas kerja yang jauh lebih baik lagi.

\section{DAFTAR PUSTAKA}

Anwar Prabu Mangkunegara, "Sumber Kerangka Berfikir Kinerja". Gramedia, Jakarta Selatan, 2015.

Dantes, Nyaoman. "Metode Penelitian". Yogyakarta: CV. Andi offsite.2015

Dewi, R. V. K., Sunarsi, D., \& Akbar, I. R. (2020). Dampak Penggunaan Teknologi Informasi dan Komunikasi Terhadap Minat Belajar Siswa di SMK Ganesa Satria Depok. Jurnal Ilmiah Wahana Pendidikan, 6(4), 1001-1007.

Edi Sutrisno "Sumber Daya Manusia", PT. Gramedia, Surabaya, 2015.

Edwin B Flippo, "Prinsip-Prinsip Sumber Daya Manusia", Edisi ke Duabelas, Erlangga, Jakarta, 2015.
G.R. Terry, George R \& Rue, Leslie W. Rue, "Dasar-Dasar Manajemen", Jakarta Bumi Aksara, Jakarta, 2016.

Handoko, "Manajemen Personalia dan Sumberdaya Manusia", Edisi Kelima, BPFE UGM, Yogyakarta, 2016.

Hariandja, Marihot T.E, "Manajemen Sumber Daya Manusia", Grasindo, Jakarta, 2015.

Hasibuan "Manajemen sumber daya manusia". Cetakan Ketujuh Belas. Jakarta: PT Bumi Aksara, 2017.

Hermawati, R., Sugiyarti, L., Handayani, R., Sunarsi, D., Alfiah, S., \& Maddinsyah, A. (2020). The Effect of Trilogy Leadership Style and Organization Culture on School Performance: Evidence form Indonesian Senior High School. PalArch's Journal of Archaeology of Egypt/Egyptology, 17(6), 8512-8537.

Insani, P. B. E. B. (2020). Hubungan Gaya Kepemimpinan Dengan Produktivitas Kerja Pegawai Bmt El Bina Insani Cugenang. Jurnal Agrita Vol, 2(1).

Kristianti, L. S., Affandi, A., Nurjaya, N., Sunarsi, D., \& Rozi, A. (2021). Pengaruh Motivasi Dan Disiplin Kerja Terhadap Kinerja Pegawai Pada Dinas Pariwisata Purwakarta. Jurnal Ilmiah PERKUSI, 1(1), 101-109.

Nurjaya, N., Affandi, A., Erlangga, H., Sunarsi, D., \& Jasmani, J. (2021). The Effect of Product Promotion and Innovation Activities on Marketing Performance in Middle Small Micro Enterprises in Cianjur. Budapest International Research and Critics Institute (BIRCI-Journal): Humanities and Social Sciences, 4(1), 528-540. (2021). Pengaruh Kompetensi Sumber Daya Manusia Dan Kemampuan Pemanfaatan Teknologi Terhadap Kinerja Aparatur Desa Pada Kantor Kepala Desa Di Kabupaten Gunungkidul, Yogyakarta. JENIUS (Jurnal Ilmiah Manajemen Sumber Daya Manusia), 4(3), 332-346.

. (2020). The Effect of Work

Stress and Work Conflict on

Copyright (C2021 Pada Penulis 
Employees Turnover Intention In Middle Small Micro Enterprises (MSMEs) In South Tangerang Region. International Journal of Educational Administration, Management, and Leadership, 51-62. . (2021). Pengaruh Etos Kerja Dan Disiplin Kerja Terhadap Kinerja Pegawai Pada Dinas Kehutanan Dan Perkebunan Kota Bogor. JENIUS (Jurnal Ilmiah Manajemen Sumber Daya Manusia), 4(2), 172-184.

Paramarta, V., Dewi, R. R. V. K., Rahmanita, F., Hidayati, S., \& Sunarsi, D. (2021). Halal Tourism in Indonesia: Regional Regulation and Indonesian Ulama Council Perspective. International Journal of Criminology and Sociology, 10, 497-505.

Pawar, A., Sudan, K., Satini, S., \& Sunarsi, D. (2020). Organizational Servant Leadership. International Journal of Educational Administration, Management, and Leadership, 63-76.

Rivai, Veithzal, "Manajemen Sumber Daya Manusia Untuk Perusahaan", Raja Grafindo Persada, Jakarta, 2015.
Safroni, Ladzi, "Manajemen dan Reformasi Pelayanan Publik dalam Konteks Birokrasi Indonesia", Aditya Media Publishing, Surabaya 2016.

Salam, Darma Setyawan, "Manajemen Pemerintahan Indonesia", Djambatan, Jakarta, 2011

Siagian Sondang P, “Kiat Meningkatkan Produktivitas Kerja", PT. Rineka Cipta, Jakarta, 2016.

Siagian, Sondang "Kiat Meningkatkan Produktivitas Kerja", PT. Rineka Cipta, Jakarta, 2015

Sunarsi, D., Akbar, I. R., Rozi, A., Khoiri, A., \& Salam, R. (2021, January). The Influence of Motivation and Work Discipline on Employee Performance at the Yogyakarta Tourism Service. In Proceeding The First International Conference on Government Education Management and Tourism (Vol. 1, No. 1, pp. 1-7).

Wilandari, D. F., Sunarsi, D., \& Mas'adi, M. (2021). Pengaruh Penilaian Kerja Terhadap Kinerja Karyawan Pada PT. Jaya Mandiri Rekabuana di Cilandak. Jurnal Ekonomi Efektif, 3(2). 